Karunathilaka, H.L.P.U., Devapriya, K.A.K. and Shanika, V.G., 2021. Effect of social and environmental factors on expressway construction in Sri Lanka. In: Sandanayake, Y.G., Gunatilake, S. and Waidyasekara, K.G.A.S. (eds). Proceedings of the $9^{\text {th }}$ World Construction Symposium, 9-10 July 2021, Sri Lanka. [Online]. pp. 280-289. DOI: https://doi.org/10.31705/WCS.2021.24. Available from: https://ciobwcs.com/papers/

\title{
EFFECT OF SOCIAL AND ENVIRONMENTAL FACTORS ON EXPRESSWAY CONSTRUCTION IN SRI LANKA
}

\author{
H.L.P.U. Karunathilaka ${ }^{1}$, K.A.K. Devapriya ${ }^{2}$ and V.G. Shanika ${ }^{3}$
}

\begin{abstract}
Expressway construction projects are one of the crucial infrastructure projects for a country. Hence, assessment of environmental and social implications prior to initiation of the expressway construction project is vital. Thus, the research aims to analyse effect of social and environmental factors on expressway construction in Sri Lanka. Initially a comprehensive literature review was done to discuss on expressway construction in Sri Lanka and environmental and social implications of expressway construction in global context. The study followed a qualitative approach. Hence, four expert interviews were carried out to explore more on the same context limiting to Sri Lanka. Experts were selected from only on-going expressway project in Sri Lanka, central expressway project. Moreover, collected data were analysed through manual content analysis.

The study findings highlighted viaduct construction, land acquisition and rock blasting as the major activities relating to environmental implications of the expressway construction projects. Thus, rational, logical, scientific, and technical selection of the routes is the most effective and efficient mean in minimizing adverse impacts. Hence planning of these activities should be done with due care by authorities only after proper feasibility studies. Further, major factors affecting social implications of the expressway construction have been identified as settlement, livelihood, public infrastructure and health and safety. Hence, resettlement action plans need to be updated to comply with the identified requirements through environmental and social factors.
\end{abstract}

Keywords: Expressway construction; Social and environmental factors; Sri Lanka.

\section{INTRODUCTION}

Development can be interpreted in various manners and has various aspects that are considerably different from each other (Amarasinghe, 2011). According to UN Documentation Research Guide (2020), development is a "multidimensional undertaking to achieve a higher quality of life for all people. Economic development, social development, and environmental protection are interdependent and mutually reinforcing components of sustainable development." Authors also stated that economic development is a well-recognized parameter through which a country's development can be measured and compared. It can be defined as "the process in which an economy grows or changes

\footnotetext{
${ }^{1}$ Department of Building Economics, University of Moratuwa, Sri Lanka, pathum.hlpuk@gmail.com

${ }^{2}$ Department of Building Economics, University of Moratuwa, Sri Lanka, kakdevapriya@uom.lk

${ }^{3}$ Department of Building Economics, University of Moratuwa, Sri Lanka, shanikav@uom.lk
} 
and become more advanced, especially when both economic and social conditions are improving" (UN documentation research guide, 2020).

Expressway infrastructure development typically requires major investments from government (Road Development Authority, 2020). In coping with the export of resources and associated regional growth, the government has set up various plans to accelerate road infrastructure development and improvement. In the Sri Lankan context road network (land base transport system) plays a predominant role in this discipline as it is the most widely used mean of transportation. (Road Development Authority, 2020), Sri Lankan Road network consists of three road classes namely Class A, Class B, and Class E. Altogether these three classes are known as national highways which has an approximate total length of $12,438.5 \mathrm{~km}$. Among them, Class E consists of expressways that have an approximate total length of $218 \mathrm{~km}$. It includes Southern Expressway (E 001), Outer Circular Expressway (E 002), Colombo-Katunayake Expressway (E 003), Andarawawe-Hambanthota Expressway (E 006). The latest expressway which is under construction is the Central Expressway Project (CEP).

Some of the legal provisions relating to expressway construction include Land Acquisition Act No 9 of 1950 and its subsequent amendments, the Land Development Ordinance (1935) and State Land Ordinance No 8 of 1947. Further, National Involuntary Resettlement Policy is considered as governing law for resettlements. Hence the expressway construction process embedded with legislative provisions is often affected by various social, environmental, economic, and time-related factors (Center for Sustainability, University of Sri Jayewardenepura, 2016).

Since expressway infrastructure usually has a long service life, the evaluation of investment alternatives and project selection requires tools and systematic methods. According to Surahyo and El-Diraby (2009), assessment of environmental and social implications prior to initiation of the expressway construction project is vital. Further, Goh and Yang (2013) stated that multiple factors such as physical, legal and political backgrounds may affect the assessment of environmental and social implications relating to expressway construction in a given country. Hence authors elaborated that the prediction and determination of a project's long-term socio-economic viability can be a precarious exercise. Therefore, it is not feasible to formulate common standards to meet the above challenges, especially in the field of assessment and mitigation of environmental and social impacts and implementation is still in the process of continuous development.

Hence the timely requirement has arisen in searching for social and environmental implications relating to expressway construction in Sri Lanka. Thus, the research aims to analyse effect of social and environmental factors on expressway construction in Sri Lanka.

\section{LITERATURE REVIEW}

\subsection{EXPRESSWAY CONSTRUCTION IN SRI LANKA}

Although Sri Lanka's Road density is higher than that of many developing countries, the standards and conditions of the road network are inadequate to meet the rapidly growing freight and passenger traffic. Most of the roads in the national highways network are still single and two-lane, more than $50 \%$ of the network has poor surface condition, and many 
portions are seriously congested (Asian Development Bank, 2018). These constraints limited the roads' contribution to the national development and economic growth, so the existing road infrastructure has to be improved and upgraded.

The expansion of the road network directly generates new markets and expands market opportunities not only for the goods market, but also for the factor market. The outcome of such expansion indirectly influences investment decisions, which then transform into industrial production, household income, and public revenue. Improvement in the quality and quantity of road networks reduces the travel time and associated costs, which directly influence the goods and factor markets through factor productivity. As pointed out by Goh and Yang (2013) the urban-rural connection roads provide market access opportunities to rural people and help them to diversify their income sources as they are linked with a greater variety of functional livelihood value chain systems.

\subsection{ENVIRONMENTAL AND SOCIAL IMPLICATIONS OF EXPRESSWAY CONSTRUCTION}

According to Surahyo and EL-Diraby (2009), the assessment of environmental and social factors associated with infrastructure construction is faced with several challenges such as lack of clear definitions, ambiguity in identifying relevant community requirements and improper planning. However, environmental implications can be discussed in detail.

\subsubsection{Environmental Implications}

Analyzing the environmental impacts of an infrastructure development project is a legislative requirement. That is mainly due to the vulnerability of the nature of the impacts. This is more serious regarding mega-scale infrastructure development projects such as expressways. Thus, environmental impact assessment together with environmental management and monitoring programs play significant roles in feasibility studies of such projects.

\section{Ambient air quality, Noise, and vibration levels}

Generally, the existing air quality of such areas in local context is within an acceptable range without any significant pollutions. However, in city areas like Mirigama and Kurunegala, and in the areas where the expressway meets highways, atmospheric conditions have been polluted to some far due to high vehicle movements.

\section{Biological environment}

According to the ecological survey of the project, the proposed expressway traverses through various natural, semi-natural and human-modified lands. However, it does not affect any national parks, sanctuaries, or declared wetlands.

The ecological survey which has covered a width of $100 \mathrm{~m}$ road corridor reveals that there are 08 main terrestrial habitat/vegetation types and 02 inland aquatic/wetland habitat types in the affected area.

The road alignment will not hinder the permanent paths of animals significantly. But there can be some localised impacts due to the obstructions. 


\section{Anticipated environmental impacts of the proposed project}

- Topography, geology, and soil

According to Dharmakeerthi and Wicramasinghe (2015), generally, above $44 \%$ of the soil has been faced some sort of degradation. In the considered scenario, soil erosion and sedimentation of soil in surrounding waterways are common as well as a critical impact. Blockages in the drainage network and silting of the nearby surface waterways are also possible. Also, air quality is affected while the transportation of soil particles by wind. Rockslides across the escarpment slope of the mountains at the road cuts is another severe issue.

- Hydrology and drainage

The major expected environmental impact is flooding, which can even destroy the construction. Also, floods cause embankment erosion and fill material stockpile erosion. According to the hazard profile of the country, floods are vulnerable to these areas during the Southwest monsoon season. Sedimentation at paddy fields and waterways is another result of floods.

- Biological environment

The most severe adverse impact on the biological environment occurs due to site clearances. There are road corridor clearances, larger area clearances at interchanges and clearances for access roads, site camps, material stores, and other temporary structures. These clearances cause the loss and fragmentation of organisms.

- Mitigation of ecological impacts

As the initial and most basic step, ROW should be designed by minimizing the impacts on sensitive areas as far as possible while maintaining an optimum balance with the cost. Providing animal overpasses and eco-ducts is also a successful design solution.

The spread of invasive alien species can be prevented by manual removal. Making the workforce aware of the threats is very important. Barricading the excavations to prevent animals from falling and sloping them to make escape easy should also be considered. According to Bakermans and Cuperus (2001) ecological compensation principle is a very productive approach for nature conservation during large-scale development projects.

\subsubsection{Social Implications}

According to Jani and Shukla (2018), social impacts can be defined as any public or private activities which change the organized living, working and behavioural patterns of any group of people. Analysing and evaluating the potential social impacts of a project is very much essential to ensure and enhance the living conditions of the inhabitants of the affected areas. Thus, a social impact assessment should highlight preventive, mitigate, managing and monitoring mechanisms against potential social impacts (Amarasinghe, 2011). A comprehensive overview of social impact dimensions namely settlements, land acquisition, livelihood and infrastructure (Gonathilaka and Zaman, 2016) has been done separately.

- Social impacts on settlements.

This need for land can result in the dislocation of the people living there. Affected communities who lose their places due to the projects, usually have deep-rooted cultural 
and social structures associated with those areas throughout a considerable period of time (Gouley and Nathan, 2017). Even in situations where people are not required to physically move, the project may still impact on their livelihoods or income generating activities, either temporarily or permanently or cause other social impacts that make settlements untenable. These processes are based on the National Involuntary Resettlement Policy (NIRP) which provides principles, rules, and norms to ensure a fair, equitable, and transparent resettlement process. (Gunatilleke, 2013)

- Impacts of land acquisition

Social impacts associated with land acquisition plays a significant role within the expressway construction. People who lose their lands will have to face various hardships such as landlessness, reduction of the profitable use of remaining lands, loss of paddy fields and unavailability of proper demarcation. However, the most critical issues arise with the acquisition of paddy lands as it reduces the availability of arable wetlands which directly affect the production of the country's staple food. Also, historical and ancestral values assigned with some lands create various issues. According to the findings of Syagga and Olima (1996) compulsory and involuntary land acquisition incurs farreaching socio-economic impact on land consumers.

- Impacts on livelihood

Expressway construction has significant social impacts on livelihood and economic activities during both construction and operation phases. The most critical impact is the inability to continue economic activities after the relocation. It becomes worst with the loss of seasonal harvest from agriculture and earnings from agricultural labour. Livelihood is further threatened due to prolonged periods of construction and authorities' less attention towards the negative community impacts to resolve the issues within a reasonable period of time.

- Impacts on infrastructure

Recognising social impacts due to any infrastructure interventions is crucial to distinguish the direct and indirect impact on the community (Mteki et al., 2017). Hence, appropriate arrangements should be made for the replacement of all community infrastructure and to ensure adequate access to essential public services.

Thus, environmental and social implications of expressway construction projects were discussed in detail.

\section{RESEARCH METHODOLOGY}

According to Kothari (2004) research methodology is the mechanism for systematic resolvent of research question. This chapter describes the approach and methodology adopted by the researcher to conduct the research. It justifies the research design together with data collection and analysing techniques. Further, it illustrates how the method has been designed in order to manage and direct the research to address the established research questions. Also, it discusses the mechanisms adopted to enhance the validity of the research.

Crossman (2020) argued that qualitative research is designed to synthesize the opinion survey. Qualitative analysis is an exploratory mechanism to uncover the patterns through the views of expertise in a particular area. Whereas quantitative analysis presents 
measurable and quantifiable data in numerical values. Thus, a qualitative approach has been used for the study as it requires opinion surveys on the context of expressway construction in Sri Lanka. Moreover, scarcity of projects relating to the context in Sri Lanka and ongoing pandemic situation led to continue study with available number of respondents. However, Table 1 indicates the profile of interviewees as follows.

Table 1: Profile of interview participants

\begin{tabular}{cccc}
\hline $\begin{array}{c}\text { Interviewee } \\
\text { Code }\end{array}$ & Designation & $\begin{array}{c}\text { Experience in expressway } \\
\text { construction }\end{array}$ & $\begin{array}{c}\text { Experience in } \\
\text { construction industry }\end{array}$ \\
\hline I1 & Project Manager & 9 years & 22 years \\
I2 & Project Engineer & 7 years & 19 years \\
I3 & Project Engineer & 6 years & 16 years \\
I4 & Project Engineer & 6 years & 15.5 years \\
\hline
\end{tabular}

Hence data collection was done through expert interviews with the participation of four experts relating to context who had more than 5 years' experience relating to expressway construction and more than 15 years of experience in the construction industry. Experts were selected from CEP stage II which is the only ongoing expressway construction project at the moment. Section 2 of CEP transverse through two administrative districts; namely, Gampaha in Western Province and Kurunegala in North-Western province. It traverses through 6 DS divisions of those districts. Section 2A: Ambepussa link road connects Gampaha and Kegalle districts and traverses through 2 DS divisions. (Road Development Authority, 2016). However, face to face interviews were done spending average of 45 minutes per interviewee. However, manual content analysis was used to analyse the qualitative data.

\section{DATA ANAYSIS}

\subsection{ANALYSIS OF THE DATA COLLECTED THROUGH EXPERT INTERVIEWS}

Expert interviews were conducted to have a deep insight into the subject matter and to investigate expert opinions on environmental and social aspects of expressway construction projects in Sri Lanka. The interview guideline has been designed based on factors identified through the literature under each aspect. Interviewees were asked to share their opinions on the context based on their own experience.

\subsubsection{Environmental Implications}

First part of the interview guideline consisted of analysing activities that creates major environmental implications within the context. Thus, interviewees were asked to discuss environmental impacts connected with major activities relating to expressway construction in detail.

According to interviewees I1, I3 and I4, when considering the rock blasting activities, the easiest way to minimize the environmental impact is to evade them as much as possible when selecting the trace. However, considering its less practicability for certain scenarios, few alternative mechanisms to minimize environmental impacts and can be taken into consideration as per the interviewees. Those are examining the possibilities to use the blasted rock materials for the expressway construction itself and to follow much effective health and safety procedures to minimise the impacts while blasting. Especially 
interviewee I1 and I4 mentioned having a proper communication between the site and the neighbourhood is crucial in rock blasting to minimise various accidents including deaths or injuries.

All interviewees highlighted that land acquisition and related procedures as key components in expressway construction project. Further I 2 highlighted the involvement of certain political interventions during these processes. Also, all interviewees highlighted, experiencing public protests due to various issues relating to compensation procedures and acquisitions. Due to these circumstances, handing over of lands to contractor at schedule time periods had been delayed causing delay claims and time extensions as well. Further, interviewees mentioned that land acquisition process consumes more time requiring various documentation, particularly while acquiring private lands for public infrastructure development projects.

Phase II of CEP runs through paddy fields and marshy lands as well. According to Interviewees I2, I3 and I4, viaduct construction is taken place when the road trace goes through marshy lands, paddy fields and crosses over highways as an alternative for embankments which is complex than a typical embankment. Therefore, according to interviewees I 2 and I 4 this combination has to be designed very carefully by considering all the possible environmental data such as irrigation patterns, soil conditions, and weather conditions. Interviewees further mentioned about public protests occurred in relation to the circumstances. According to the findings of the interviewees, decisions were already taken to replace the embankments with viaducts after carefully considering the forwarded facts. Thus, based on the opinions of all interviewees, land acquisition, rock blasting and viaduct construction have been identified as most influential activities relating to environmental implications of the expressway projects.

\subsubsection{Social Implications}

Thereafter, under the part II of interview guideline, interviewees were further asked to discuss in detail about social implication factors relating to expressway construction projects named settlement, livelihood, public infrastructure and health and safety. Those factors were discussed thoroughly based on opinions of interviewees as follows.

- Settlement

According to interviewees I1, I2 and I4 implementation of the project led to a drastic change in social network in affected the community. Further I1 mentioned difficulties in attributing relevant socio-economic characteristics to the land-use changes. Also, Interviewee I3 said that settlement interconnects with cultural values, experience of cultural marginalized, exploitation of cultural monuments, loss of natural and cultural heritages, disruption of social network, changes in demographic structure of the community, social differentiation and inequality, social tension and violation. Hence the interviewee highlighted the importance of carefully planned strategies to ensure the smooth functioning of the community after the relocation.

Thus, adverse impacts on settlements should be considered to the fullest possible extent as per both I2 and I4. Also, any difficulties in addressing such requirements should be properly convinced to the resettling community to avoid public misunderstanding (I4). Hence all interviewees stressed that rational, logical, scientific and technical selection of the route for an expressway project is a must. Further as per all four interviewees, mitigating the inevitable negative social impacts of the projects in compliance with the relevant legal provisions as well as the internationally agreed standards and guidelines of 
redressing public grievances stemming from national development projects is another aspect to be prioritised. Thus, these aspects reinforce the need for successful resettlement plans.

\section{- Livelihood}

Interviewees expressed their opinions on livelihood depicting some key concerns; work at home environment or neighbourhood, disruption of daily living practice, recreation opportunity and facilities, aesthesis quality, physical quality of housing and availability of housing facilities. Further, Interviewees I 2 and I 3 pointed out variables such as poverty status, earning and employment opportunities and asset holding relating to social aspects.

Sustainably restoring livelihoods is a significant mitigation measure that should be adhered to (I1, 12 and I4). However, financial compensations are given to cover the loss of earnings during the period of resettlement and to cover the income from affected investments. Yet Interviewee 12 stated that the livelihood restoration has a much broader perspective beyond that. However, Interviewees I3 and I4 suggested that ability of affected community to adapt new surroundings highly depends on available infrastructure facilities.

\section{- Public Infrastructure}

Interviewees I2, I3 and I4 said that even though CEP is one of the major infrastructure development projects in country it may cause frequent damages to the existing infrastructure during its construction. Especially due to high traffic volume and frequent mobilization of heavy vehicles existing road networks may damage. Further as per interviewees I1 and I2, power transmission lines, telecommunication lines and water distribution lines can also disrupt due to certain construction requirements. Free and natural flow of waterways affect in places where expressway traverses through paddy lands and irrigation canals creating impacts on cultivation in highlands as well (I2). Nevertheless, noisy and dusty construction activities may interrupt calm and smooth functioning of community infrastructure facilities such as schools, temples, hospitals, hotels, religious centers, cemeteries, public parks and playgrounds (I1, I3 and I4).

- Public Safety and Health

The absence of proper precautionary measures causes serious health and safety issues for both inhabitants and the workforce in this type of huge construction projects (I1). Some of the associated activities such as frequent mobilization of heavy vehicles, explosive usage, deep cuts, and landfilling in mountainous sites bring life threats for workers and inhabitants (I2 and I3). Interviewee I3 mentioned that unauthorized and unsafe entrances and site visits may even cause serious accidents as CEP is a new experience for inhabitants.

People living within about $200 \mathrm{~m}$ of the road corridor expose to polluted air and noise releasing from construction activities facing the risk of asthma development and lung function reductions (I4). Also, improper disposal of solid and liquid discharge from the site can directly contribute to contamination of water sources and the spread of diseases such as dengue providing rich breeding grounds around sites (I1 and I3). All interviewees pointed out significance of assuring public safety and health during both construction and operation phases, especially with greater care for higher population density areas. Strictly 
adhering to the security guidelines and assuring them with proper supervision is the best way to overcome health and safety issues (I2 and I4).

Social impact mitigation plays the most critical role in this project as it involves a significant amount of land acquisition which is occupied by individuals and institutions. However, overall project objectives can only be achieved with the proper restoration of affected local communities along with their social and environmental requirements. For that identified environmental and social implications relating to the context needs to be properly addressed.

\section{CONCLUSIONS}

The efficiency of the transport system has paramount importance concerning the country's economic and infrastructure development. Sri Lankan road network consists of expressways which have an approximate total length of $218 \mathrm{~km}$. Hence, expressway construction projects are critical due to their huge capital requirement, associated responsibility with the public money, the huge physical size of the project and occupation of large areas of land, social and environmental impacts, and externalities. However, expressway construction undoubtably consumes huge capital due to its environmental and social interferences.

The study findings highlighted viaduct construction, land acquisition and rock blasting as the major activities relating to environmental implications of the expressway construction projects. Thus, rational, logical, scientific, and technical selection of the routes is the most effective and efficient mean in minimizing adverse impacts. Hence planning of these activities should be done with due care by authorities only after proper feasibility studies. Further, major factors affecting social implications of the expressway construction have been identified as settlement, livelihood, public infrastructure and health and safety. Relocation plays a critical role in the expressway construction. However, land acquisition-related legislative enactments are not capable to address the broader social and environmental impacts of relocation such as income restoration and grievance redressing (Asian Development Bank, 1999). To mitigate the related issues, resettlement action plans need to be updated to comply with the identified requirements.

\section{REFERENCES}

Amarasinghe, S.H., 2011. Managing the socio-economic impacts due to compaction operations during construction of Southern expressway. Thesis (PhD). University of Moratuwa.

Asian Development Bank, 1999. Developing a national policy on involuntary resettlement. Manila: Asian Development Bank.

Asian Development Bank, 2018. Sri Lanka: National highways sector projects. Philippines: Asian Development Bank.

Bakermans, M., and Cuperus, R., 2001. Ecological compensation in Dutch highway planning. Environmental Management, pp. 75-89.

Center for Sustainability, University of Sri Jayewardenepura., 2016. Draft final environmental impact assessment report. Road Development Authority.

Crossman, A., 2020. An Overview Of Qualitative Research Methods [Online]. New York, Thought Co. Available from: https://www.thoughtco.com/qualitative-research-methods-3026555 [Accessed 20 April 2021]

Dayanath, G., and Ichihashi, M., 2020. Assessment of the intended outcomes of the newly built expressway in Sri Lanka. Journal of Applied Business and Economics, 22(11), pp. 76-91. 
Dharmakeerthi, R. and Wicramasinghe, W., 2015. Status and national priorities of soil resources in Sri Lanka [Online]. Colombo, Soil Science Society of Sri Lanka. Available from: http://www.fao.org/fileadmin/user_upload/GSP/docs/asia_2015/Sri_Lanka_ASP_2015.pdf [Accessed 22 April 2021].

Goh, K.C. and Yang, J., 2014. Importance of sustainability-related cost components in highway infrastructure: perspective of stakeholders in Australia. Journal of Infrastructure Systems, 20(1), p.04013002.

Gonathilaka, S. and Zaman, M., 2016. Assessing the social impact of development projects. advances in asian human-environmental research. Cham: Springer.

Gouley, C. and Nathan, F., 2017. Livelihoods restoration planning: Practical Insights From The Case of Sand Mining Workers at The Nachtigal Hydropower Project (Cameroon). In: IAIA Special Symposium on Resettlement and Livelihoods. Manila Philippine: International Association for Impact Assessment. pp. 69-70.

Gunatilleke, G., 2013. Legal and policy frame work: An overview of the National Involuntary Resettlement Policy (NIRP). In: 48 ${ }^{\text {th }}$ Open Forum on Poverty - Development, Displacement and Resettlement. Colombo: The Centre for Poverty Analysis.

Jani, H. and Shukla, N., 2018. Social impact assessment of road infrastructure projects. Global Journal of Commerce and Management Perspective, 7(1), pp. 53-73.

Kothari, C., 2004. Research methodology: methods and techniques. New Delhi: New Age International.

Mteki, N., Murayama, T. and Nishikizawa, S., 2017. Livelihood adaptation strategies in Dar es Salaam city, Tanzania. In: IAIA Special Symposium on Resettlement and Livelihoods. Manila, Philippine: International Association for Impact Assessment. pp. 65 - 66.

Road Development Authority, 2016. Resettlement action plan - Central expressway project - Appendixes. Colombo: Road Development Authority.

Road Development Authority, 2020. Colombo, expressway operation maintenance and management division [Online]. Road Development Authority. Available from: http://www.rda.gov.lk [Accessed 22 October 2020].

Surahyo, M. and EL-Diraby, T., 2009. Schema for interoperable representation of environmental and social costs in highway construction. Journal of Construction Engineering And Management, 135(4), pp. 254266.

Syagga, P. and Olima, W., 1996. The impact of compulsory land acquisition on displaced households: The case of the third Nairobi water supply project Kenya. Kenya: University of Nirobi.

UN Documentation Research Guide, 2020. UN documentation research guide [Online]. New York, United Nations Dag Hammarskjöld Library. Available from: http:// www.research.un.org [Accessed 13 December 2020]. 